CDD: 025.527

\title{
ESTUdO COM AS PATENTES PRODUZIDAS E O PERFIL dOS INVENTORES DOS INSTITUTOS FEDERAIS DE EDUCAÇÃO, CIÊNCIA E TECNOLOGIA
}

\author{
STUDY ABOUT THE PRODUCED PATENTS AND THE PROFILE OF THE INVENTORS \\ OF THE FEDERAL INSTITUTIONS OF EDUCATION, SCIENCE AND TECHNOLOGY
}

\section{Valmira Perucchi ${ }^{1}$ \\ Suzana Pinheiro Machado Mueller ${ }^{2}$}

\begin{abstract}
Resumo: Descreve e analisa patentes depositadas pelos atuais Institutos Federais de Educação, Ciência, e Tecnologia (IFs), fundados em 2008, e pelos Centros Federais de Educação Tecnológica (CEFETs) que os precederam, recuperadas na Base de Dados do Instituto Nacional de Propriedade Intelectual (INPI), até 31 de dezembro de 2012. O levantamento na base do INPI identificou 44 patentes depositadas, das quais 14 publicadas e 30 em sigilo. Essas patentes são descritas segundo dois conjuntos de variáveis: relacionadas ao próprio documento (tipo de patente, distribuição geográfica, titulares, inventores, data de depósito, data de publicação e seção da Classificação Internacional de Patentes (CIP)); e variáveis relacionadas aos inventores (sexo, bolsa de produtividade, grupos de pesquisa, enquadramento funcional e titulação), essas identificadas na base de currículos da Plataforma Lattes. Resultados mostram quatro depósitos de patentes pelos CEFETs e 40 depósitos de patentes pelos IFs a partir de 2008 até a data de corte desta pesquisa. A maioria dessas patentes está classificada na seção A (necessidades humanas) da CIP. A Região Nordeste se destaca como maior depositante, e nela especialmente o IF da Bahia. Foram notadas poucas mulheres entre os inventores, e também poucas parcerias, e entre essas parcerias, apenas uma com indústria.
\end{abstract}

Palavras-chave: Patentes. Institutos Federais de Educação. Ciência e tecnologia. Produção de patentes. Instituição de ensino. Perfil dos inventores de patentes.

Abstract: This research describes and analyzes patents deposited by the present Federal Institutes of Education, Science and Technology (IFs), founded in 2008, and by the Federal Centers of Technological Education (CEFETs) that preceded them. These patents were retrieved from the database of the National Institute for Intellectual Property (INPI), till December $31^{\text {st }}, 2012$. The survey in the INPI database identified 44 patents, from which 14 were published and 30 of them were trade secret. These patents are described according to two sets of variables with reference to the document itself (type of patent, geographic distribution, patentees, inventors, deposit date, publication date and section of the International Classification of Patents (ICP); and variables with regard to the inventors (sex, productivity scholarship, research groups, functional framework and academic degree). These are identified in the curricula vitae base of the Lattes Platform. Results show four

\footnotetext{
${ }^{1}$ Bibliotecária do Instituto Federal de Educação. Doutoranda em Ciência da Informação pela Universidade de Brasília. Brasília, DF. Brasil - E-mail:

${ }^{2}$ Professora do Programa de Pós-Graduação em Ciência da Informação da Universidade de Brasília. $\mathrm{PhD}$, Information Studies. Brasília, DF. Brasil - E-mail:
}

Recebido em: 27/05/2013 - Aceito em: 02/12/2013. 
deposits of patents fulfilled by the CEFETs and 40 patents deposited by the Federal Institutes (IFs) from 2008 until the conclusion of this research. The majority of these patents are classified in section A (human needs) of the ICP. The northeastern region is highlighted as the largest depositor, especially the Federal Institute of Bahia. Among the inventors, there are few women as well as few partnerships, and among these, just one with industry.

Keywords: Patents. Federal Institutes of Education. Science and technology. Production of patents. Teaching institution. Profile of the patents ${ }^{\prime}$ inventors.

\section{INTRODUÇÃO}

O conhecimento produto de atividade inventiva, principalmente se possui valor comercial, deve ser protegido por meio da patente. As patentes para as quais foi solicitado registro, sejam elas publicadas ou estando ainda em sigilo, são um dos principais modos de mensurar a produção do conhecimento. A patente é usada para designar o documento que descreve invenção resultante de uma criação inédita reconhecida pela entidade competente, que no Brasil é o Instituto Nacional de Propriedade Intelectual (INPI). A patente só é concedida depois de examinada por peritos, os quais, entre outros pontos, se certificam de que de fato se trata de uma atividade inventiva. Quando há a aprovação e a patente é concedida, o seu detentor (que nem sempre é o seu inventor) tem sua propriedade confirmada, podendo cobrar dos interessados em usar a invenção (royalties). Pelo que representa em termos de criação e pelo seu valor comercial, o conjunto de patentes produzido em uma instituição, estado ou país é um indicador de desenvolvimento e assim sua ocorrência é foco de interesse para essas entidades e objeto de estudo de pesquisadores.

Existe uma discussão na literatura, retratada por Stokes (2005), sobre a natureza das atividades de pesquisa que tem tido repercussão em políticas públicas de financiamento da pesquisa e na concepção de instituições de ensino superior. Vannevar Bush se tornou representante de um dos extremos nessa discussão, quando, em seu relatório Science, the Endless Frontier (1945), apresentado ao então Presidente dos Estados Unidos, Franklin Roosevelt, após a Segunda Guerra Mundial, defendeu a ideia que o objetivo primordial da ciência é o entendimento e não a aplicação de novos conhecimentos, que a função dos pesquisadores é avançar o conhecimento, sem preocupações com usos desse conhecimento. Ciência pura seria um ponto extremo de um contínuo e ciência aplicada e as tecnologias estariam no 
outro extremo, essas sim, visando a solução de problemas sociais. Mais do que a distância entre os extremos haveria uma tensão separando os praticantes das duas modalidades de pesquisa, sendo inapropriado o envolvimento do cientista puro com a aplicação de seus resultados. Segundo essa visão, cientistas devem ser educados para descobrir o que não se sabe, para avançar o nosso conhecimento sobre qualquer aspecto da natureza ou sociedade, não para resolver problemas sociais. A contribuição dos cientistas à sociedade seria o entendimento dos fenômenos, conhecimento que outros poderão usar no desenvolvimento de soluções de problemas sociais. O outro extremo, na discussão, é defendido por Stokes em seu livro o Quadrante de Pasteur (2005), e privilegia a interação entre ciência e tecnologia e a não linearidade do processo de criação da inovação. Stokes, citando Pasteur como exemplo, argumenta que frequentemente o cientista puro é motivado por problemas sociais e contribui para sua solução.

Embora Bush tenha ficado conhecido por defender, nos anos do pós-guerra, a separação entre ciência pura e ciência aplicada, essa posição é muito mais antiga. De acordo com Stokes (2005), "as origens institucionais e ideológicas desse ponto de vista remontam às origens do ideal da investigação pura do mundo grego [... e] as contribuições para essa visão podem ser encontradas na Europa e na América nos séculos XIX e XX” (p.52). Também no Brasil do início do século XX essas ideias estavam presentes, tanto na educação quanto no fomento. Em 1909, o então presidente Nilo Peçanha, aprovou a fundação das Escolas de Aprendizes e Artífices, um tipo de instituição de educação de nível médio que visava à preparação de trabalhadores com conhecimentos técnicos, alternativa à escola tradicional de cunho acadêmico. Essas escolas foram fundadas em 19 estados: Goiás, Mato Grosso, Bahia, Ceará, Sergipe, Alagoas, Pernambuco, Paraíba, Rio Grande do Norte, Piauí, Maranhão, Amazonas, Pará, São Paulo, Minas Gerais, Rio de Janeiro, Espírito Santo, Paraná e Santa Catarina. Ao longo dos anos, essas escolas receberam diferentes denominações, como mostra a Figura 1. A partir de 1978, com a criação dos Centros Federais de Educação Tecnológica (CEFETs), foram acrescentados cursos de nível superior aos existentes cursos de nível médio. 


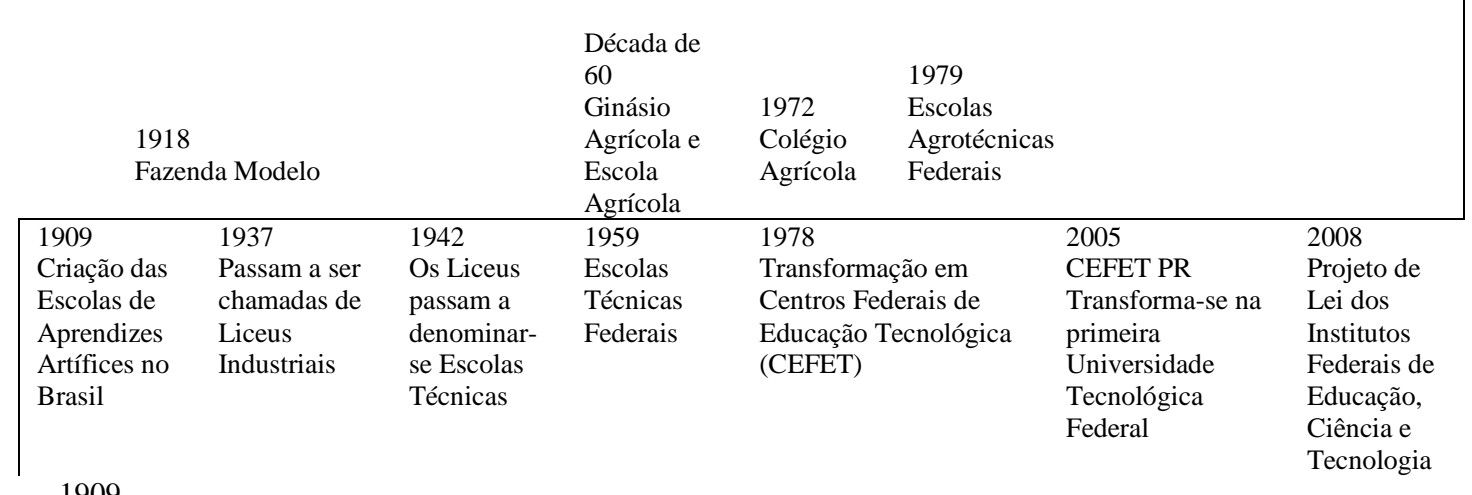

1909

FIGURA 1 - Cronologia das denominações das instituições federais de educação profissional, científica e tecnológica

FONTE: UM SÉCULO..., (2009?).

Em 2008, 100 anos após a fundação das Escolas de Aprendizes e Artífices, suas sucessoras foram alvo de ampla reforma: a Lei 11.892 de 29 de dezembro de 2008 criou 38 Institutos Federais de Educação, Ciência e Tecnologia (IFs) a partir da junção das escolas existentes em cada Estado (BRASIL, 2008). O ensino de ciência foi então adicionado ao currículo que já incluía tecnologia. Data de 2008, portanto, a atual configuração desses IFs, cujos objetivos educacionais pretendem enfatizar a relação entre ciência e tecnologia por meio de pesquisas e desenvolvimento tecnológico de processos, produtos e serviços. Segundo a citada Lei 11.892, a vocação dos IFs é "a educação voltada para a ciência e tecnologia" (BRASIL, 2008), especialmente para a solução de problemas práticos da sociedade. Os IFs foram concebidos como entidades diferentes das universidades, o que sugere forte influência, até hoje, da visão que separa a pesquisa pura da pesquisa para aplicação ou uso. No entanto, se a fundação dos IFs atesta a intenção da separação entre ciência e tecnologia na formação dos futuros profissionais, essa diferença não é clara, nem na Lei que instituiu os IFs e nem, aparentemente, na prática.

Nos países em desenvolvimento, como o Brasil, são as instituições de ensino, especialmente as universidades, o locus mais frequente da produção de conhecimento científico e também de patentes, talvez por estar a indústria nacional, em grande parte, ainda em desenvolvimento. Também é de conhecimento público que a produção brasileira de artigos científicos é bastante superior à produção de patentes registradas, fato que parece refletir a característica de nosso sistema educacional que privilegia a 
educação acadêmica. Da mesma forma, há literatura nacional bastante extensa sobre a produção de artigos científicos nas várias áreas do conhecimento, mas, comparativamente não parece haver muitos estudos publicados sobre a produção de patentes. Neste contexto, esta pesquisa visa contribuir para essa literatura, e têm como objeto de estudo as patentes produzidas pelos IFs. A pergunta que motiva o estudo: é possível perceber mudanças na produção de patentes pelos IFs após a implementação da Lei 11.892 de 29 de dezembro de 2008 ?

O texto está organizado da seguinte forma: após esta introdução segue uma seção que comenta a literatura sobre conceitos relacionados ao sistema de patentes e à sua relevância como forma de proteção dos direitos de propriedade. A seguir, descrevem-se os procedimentos metodológicos que orientaram este estudo, e, após, os seus resultados são expostos e comentados. Finalmente, na última seção, algumas considerações sobre os resultados obtidos com o estudo.

\section{RELEVÂNCIA DA PATENTE PARA A DE PROTEÇÃo DO CONHECIMENTO}

A relevância do patenteamento de um conhecimento está bem descrita por Branco et al. (2011, p. 21): "patente é uma forma de proteger o conhecimento e garantir a exploração comercial de uma criação pelo seu inventor, além de ser um recurso legal que proíbe e responsabiliza terceiros não autorizados a explorar comercialmente tal conhecimento." Para que haja a concessão da patente, no entanto, é necessário que determinados requisitos sejam preenchidos: novidade, atividade inventiva e aplicação industrial. (BRASIL, 1996; JANNUZZI; SOUZA, 2008; OCDE, 2009 e SPINAK, 2003).

O INPI conceitua patente como um título de propriedade temporária sobre uma invenção ou modelo de utilidade, outorgado pelo Estado aos inventores e outras pessoas físicas ou jurídicas detentoras de direitos sobre a criação. Em contrapartida, os inventores e depositantes se obrigam a revelar detalhadamente o conteúdo técnico da matéria protegida pela patente (INPI, 2013). Para a Organização para a Cooperação e Desenvolvimento Econômica (OCDE), as patentes constituem uma forma de proteger os inventos desenvolvidos, e como tal são suscetíveis de 
interpretação como indicadores da atividade inventiva (OCDE, 2009, p. 15).

A patente declara a existência de um monopólio temporário, outorgado pelo Estado ao inventor ou a outrem por ele indicado, reconhecendo-lhe o direito de propriedade e de exploração da invenção descrita em documento. A patente pode ser concedida a pessoas físicas ou jurídicas, isoladamente ou em grupo (FRANÇA, 2000, p. 153-154). As descobertas e as invenções são, cada vez mais, produto de pesquisas, e devem ser protegidas pela propriedade industrial ou qualquer outra forma de resguardá-las, para que o conhecimento tenha na proteção das patentes de invenção ou de modelos de utilidade o seu uso restringido: livre para uso em pesquisa e desenvolvimento, proibido para a produção industrial sem a autorização de seu titular (MACEDO; BARBOSA, 2000, p.29).

A invenção é um ato intelectual que se configura por trazer uma novidade. "A invenção muitas vezes se materializa em produtos ou processos de fabricação e provoca um avanço real nas atividades industriais, podendo ser por isso bastante valorizada, tornando-se mesmo um bem econômico" (FRANÇA, 2000, p. 153).

Macedo e Barbosa (2000) esclarecem sobre a diferença entre invenção e inovação

Invenção pode ser descrita como uma nova solução para um problema técnico de produção. O problema pode ser antigo ou novo; respectivamente, de como criar ou aperfeiçoar um processo químico ou um novo produto para atender a uma necessidade antes inexistente. Mas a solução, para ser uma invenção, precisa ser obrigatoriamente nova, ou seja, que ninguém haja criado anteriormente a ideia ou, pelo menos, que ninguém tenha divulgado ou disponibilizado o acesso de sua informação ao público.

Inovação é a introdução de novas mercadorias ou de tecnologias em mercado, desde que nessa forma esteja contida em sua etapa inicial uma fase de inventividade. Considerada assim, a inovação tem sua origem em uma invenção, prosseguindo até a comercialização da própria invenção ou da mercadoria que a contém, pois o processo inovativo, por definição, contém sempre a comercialização. (MACEDO; BARBOSA, 2000, p.23).

No Brasil há duas leis em vigor, que tratam da patente e assuntos correlatos, são: Lei $n^{\circ}$ 9.279, de 14 de maio de 1996 (Lei de Propriedade Industrial), regula direitos e obrigações relativos à propriedade industrial considerado o seu interesse social e o desenvolvimento tecnológico e econômico do País (BRASIL, 1996); e a Lei $\mathrm{n}^{\circ} 10.973$ (Lei de Inovação Tecnológica) que estabelece medidas de incentivo à 
inovação e à pesquisa científica e tecnológica no ambiente produtivo, com vistas à capacitação e ao alcance da autonomia tecnológica e ao desenvolvimento industrial do País (BRASIL, 2004).

O sistema de patentes está ancorado em consenso universal e o instrumento de patente

\begin{abstract}
é um dos principais componentes do sistema internacional de propriedade industrial. Este sistema é considerado como o conjunto de leis e tratados que tem o objetivo de proteger todas as formas de ativos intangíveis da indústria, ou seja, a riqueza não material gerada paralelamente à fabricação de bens materiais, e representada por valores voláteis, tais como a tecnologia utilizada, o conceito da empresa junto à clientela, o seu reconhecimento frente aos concorrentes (FRANÇA, 2000, p. 159).
\end{abstract}

Garcia (2006) aponta vantagens no patenteamento, argumentando que a patente garante o monopólio ao seu detentor e que o licenciamento da tecnologia a empresas reverte em dividendos que ajudariam no financiamento de futuras pesquisas. Por outro lado, Garcia cita como desvantagens as dificuldades na solicitação do patenteamento, tais como a demora e o custo, e também o desejo de manter o sigilo.

Encontram-se na literatura poucos estudos que analisam o depósito de patentes produzidas em instituições de ensino superior brasileiras, tais como: Assumpção (2000); Amadei e Torkomian (2009); Castro, Jannuzzi e Mattos (2007); Oliveira e Velho (2009); Serafini et al. (2011) e Souza, Barbastefano e Pereira (2011). Dentre eles, o estudo de Oliveira e Velho, Patentes acadêmicas no Brasil: uma análise sobre as universidades públicas paulistas e seus inventores, publicado em 2009, foi especialmente relevante para este estudo porque inspirou a estratégia adotada, isto é, a busca por dados das patentes e de seus inventores.

\title{
3 PROCEDIMENTOS METODOLÓGICOS
}

Para atingir os objetivos que orientam este estudo, os procedimentos metodológicos foram planejados para identificar patentes depositadas ou solicitadas pelos IFs, e perceber aumento de solicitações e depósitos depois da implementação da Lei 11.892 de 29 de dezembro de 2008, que criou os IFs. A identificação foi feita por meio de busca na Base de Dados do INPI e limitou-se àquelas patentes com pedido nacional de depósito. A busca foi feita no dia 31 de dezembro de 2012 e foram 
consideradas apenas as patentes depositadas até essa data. A expressão de busca foi Instituto Federal, sem aspas ou qualquer outra marcação, no campo nome do depositante/titular. Note-se que as bases são dinâmicas e o retratado nesse estudo reflete a situação do dia da busca, 31 de dezembro de 2012. Foram incluídas neste estudo as patentes identificadas como depositadas ou solicitadas pelos professores e pesquisadores dos IFs. Para complementar o estudo, características dos inventores também foram identificadas, na base da Plataforma Lattes.

A análise relacionada às patentes considerou as seguintes variáveis: tipo de patente, distribuição geográfica, titulares, inventores, data de depósito, data de publicação e seção da Classificação Internacional de Patentes (CIP). Note-se que titulares são os IFs, e inventores, as pessoas que realizaram a pesquisa. Para os inventores foram analisadas as variáveis: sexo, bolsa de produtividade, participação em grupos de pesquisa, titulação, enquadramento funcional e existência (ou não) de outras patentes depositadas.

A pesquisa na Base de Dados do INPI foi pela palavra-chave Instituto Federal no campo nome do depositante/titular que recuperou 48 patentes, tendo sido aproveitadas 40 que tinham como titular um IF. Dessas, 30 estão com os processos em sigilo. De acordo com a Lei 9.279, em seu Art. 30, “o pedido de patente será mantido em sigilo por 18 meses contados de depósito ou da prioridade mais antiga, quando houver, após o que será publicado" (BRASIL, 1996). Isso significa que não se pode ter acesso a todas as informações que caracterizam essas patentes, mas é possível saber seus códigos de identificação, titulares e ano de depósito, e por isso entraram no levantamento. As 10 patentes restantes foram publicadas e o acesso ao documento que a descreve é possível.

As patentes depositadas no INPI e já publicadas têm uma capa com várias informações, de forma padronizada: código de identificação, data de depósito, data de publicação, sua classificação segundo a CIP, título, titulares, inventores, resumo e desenho da invenção. Neste estudo foram coletadas todas essas informações com exceção do resumo e desenho. O sistema CIP utiliza um conjunto de letras e números que representam seção, subseção, classe, subclasse e grupos. Por exemplo: A01B 1/00, onde, A Seção, 01 Classe, B Subclasse, 1/00 Grupo Principal (INPI, 2011). A 
CIP estabelece as seguintes seções: Seção A (necessidades humanas); Seção B (operações de processamento e transporte); seção C (química e metalurgia); seção D (têxteis e papel); seção E (construções fixas); seção F (engenharia mecânica, iluminação, aquecimento, armas e explosão); seção G (física) e seção H (eletricidade). Interessa ao estudo verificar em que seção as patentes identificadas estão classificadas porque elas indicam seu campo de atuação. Nos casos em que a patente apresenta várias classificações, considerou-se a primeira, e posteriormente, as subsequentes, para identificar as seções com maior ocorrência. Além da CIP, as patentes recebem também um código que transmite várias informações, entre elas a natureza da proteção concedida, que pode ser: patentes de invenção (PI), modelo de utilidade (MU), desenho industrial e indicações geográficas. Essa informação também é de interesse deste estudo porque identifica o tipo de invenção.

A identificação dos inventores foi feita com base no documento da patente, e a busca dos dados para as variáveis relacionadas aos inventores foi realizada na Plataforma Lattes, no site: http://buscatextual.cnpq.br/buscatextual/. As informações coletadas foram anotadas em um formulário.

\section{RESULTADOS OBTIDOS}

Seguindo os critérios propostos, foram identificadas 40 patentes que têm entre seus depositantes pelo menos um IF. Entre essas patentes, 30 (75\%) estavam em sigilo na época do levantamento, permitindo comentário sobre apenas algumas características. As demais 10 (25\%) patentes já foram publicadas, estando disponíveis na íntegra na Base de Dados do INPI. Conforme descrito na seção Procedimentos Metodológicos, as varáveis analisadas estão divididas em dois grupos, variáveis de patente que constam no Quadro 1 e variáveis de inventor apresentadas no Quadro 2.

\subsection{Resultados relacionados às variáveis patentes}

As patentes estão listadas em ordem crescente pela data de depósito. Os dados foram obtidos mediante exame da pagina inicial (capa) das patentes publicadas e de informações constantes na base do INPI para as patentes em sigilo. 
QUADRO 1 - Patentes depositadas e publicadas pelos IFs que constam na Base de Dados do

\section{INPI*}

\begin{tabular}{|c|c|c|c|c|c|c|}
\hline $\begin{array}{l}\text { CÓDIGO DE } \\
\text { IDENTIFICAÇÃO } \\
\text { (tipo de patentes)** }\end{array}$ & TÍTULO & $\begin{array}{l}\text { INSTITUIÇÕES/ } \\
\text { TITULARES }\end{array}$ & INVENTORES & $\begin{array}{c}\text { ANO } \\
\text { DEPÓSITO }\end{array}$ & $\begin{array}{c}\text { ANO } \\
\text { PUBLI- } \\
\text { CAÇÃO }\end{array}$ & CIP \\
\hline PI0805077-5 & $\begin{array}{l}\text { Processo de separação e briquetagem } \\
\text { da parte metálica contida em } \\
\text { resíduos provenientes do corte de } \\
\text { rochas ornamentais }\end{array}$ & $\begin{array}{l}\text { IF Espírito Santo; } \\
\text { Servigran Ind. e Com.; } \\
\text { Fundação de Amparo } \\
\text { a Pesquisa do Espírito } \\
\text { Santo }\end{array}$ & $\begin{array}{l}\text { José de Oliveira; } \\
\text { Itamar Cezario }\end{array}$ & $15 / 07 / 2008$ & $24 / 01 / 2012$ & $\begin{array}{l}\text { C22B } 1 / 00 \\
\text { C22B } 1 / 14\end{array}$ \\
\hline MU8802959-0 & Defumador de pescados & IF Bahia & Cristiane Silvão & $22 / 07 / 2008$ & $11 / 05 / 2010$ & $\begin{array}{l}\mathrm{A} 23 \mathrm{~B} 4 / 044 \\
\mathrm{~A} 23 \mathrm{~B} 4 / 052\end{array}$ \\
\hline PI0903171-5 & $\begin{array}{l}\text { Método para sinterização de } \\
\text { cerâmicas varistoras em forno micro- } \\
\text { ondas adaptado }\end{array}$ & IF Maranhão & $\begin{array}{l}\text { Jomar Vasconcelos; } \\
\text { Péricles Furtado }\end{array}$ & $26 / 05 / 2009$ & $08 / 02 / 2011$ & C04B 35/478 \\
\hline PI0903957-0 & $\begin{array}{l}\text { Método de quantificação de } \\
\text { glicerina, oriunda do processo de } \\
\text { obtenção do biodiesel, por } \\
\text { cromatografia em fase gasosa }\end{array}$ & $\begin{array}{l}\text { IF Bahia } \\
\text { SENAI } \\
\text { Univ. Fed. da Bahia }\end{array}$ & $\begin{array}{l}\text { Alexandre } \\
\text { Machado; } \\
\text { Jailson Andrade; } \\
\text { Núbia Ribeiro; } \\
\text { Rogério Rodrigues }\end{array}$ & $26 / 08 / 2009$ & $06 / 09 / 2011$ & G01N 30/00 \\
\hline MU8903003-6 & $\begin{array}{l}\text { Adição de cinzas da casca do café } \\
\text { em massas cerâmicas para pisos e } \\
\text { revestimentos }\end{array}$ & $\begin{array}{l}\text { IF Bahia } \\
\text { Univ. Fed. do RN }\end{array}$ & $\begin{array}{l}\text { Eduardo Dultra; } \\
\text { Wilson Acchar }\end{array}$ & $11 / 09 / 2009$ & $26 / 04 / 2011$ & $\begin{array}{l}\text { C04B 33/135 } \\
\text { C04B 33/04 }\end{array}$ \\
\hline MU8903002-8 & $\begin{array}{l}\text { Aproveitamento de resíduos de cinza } \\
\text { do bagaço da cana-de-açúcar em } \\
\text { massas cerâmicas }\end{array}$ & $\begin{array}{l}\text { IF Bahia } \\
\text { Univ. Fed. do RN }\end{array}$ & $\begin{array}{l}\text { Wilson Acchar; } \\
\text { Raimundo } \\
\text { Paranhos; } \\
\text { Antônio Santos }\end{array}$ & $16 / 11 / 2009$ & $12 / 07 / 2011$ & $\begin{array}{l}\text { C04B 33/135 } \\
\text { C04B 33/04 }\end{array}$ \\
\hline PI0904946-0 & $\begin{array}{l}\text { Secador de ar comprimido por } \\
\text { refrigeração através de compressão } \\
\text { mecânica com expansão direta e com } \\
\text { unidade condensadora remota }\end{array}$ & IF Santa Catarina & Julio da Silva & $24 / 11 / 2009$ & $12 / 07 / 2011$ & \begin{tabular}{|l} 
B01D 53/26 \\
F04B 39/16
\end{tabular} \\
\hline PI0904947-9 & $\begin{array}{l}\text { Monitoramento de atividades de } \\
\text { natação com RFId }\end{array}$ & IF Santa Catarina & $\begin{array}{l}\text { Márcio Doniak; } \\
\text { Ponciano Grelf }\end{array}$ & $24 / 11 / 2009$ & 19/07/2011 & \begin{tabular}{|l|} 
G04F 13/00 \\
G06K 19/07 \\
G07C $1 / 22$ \\
\end{tabular} \\
\hline PI0920084-3 & (em sigilo) & IF Maranhão & (em sigilo) & $01 / 12 / 2009$ & (em sigilo) & (em sigilo) \\
\hline MU8903119-9 & Método de contorno ativo pSnakes & IF Ceará & $\begin{array}{l}\text { Auzuir Ripardo de } \\
\text { Alexandria }\end{array}$ & $21 / 12 / 2009$ & $03 / 01 / 2012$ & $\begin{array}{l}\text { A61B } 8 / 00 \\
\text { G06T 7/00 } \\
\end{array}$ \\
\hline PI1003821-3 & $\begin{array}{l}\text { Óculos-mouse: mouse controlado } \\
\text { pelos movimentos da cabeça do } \\
\text { usuário }\end{array}$ & IF Sul-Rio-Grandense & $\begin{array}{l}\text { Alexandre Sampaio; } \\
\text { Andréia Pereira; } \\
\text { Cleber Quadros; } \\
\text { Filipe Carvalho; } \\
\text { Mário B.Machado } \\
\end{array}$ & $23 / 04 / 2010$ & $14 / 02 / 2012$ & $\begin{array}{l}\text { G06F 3/03 } \\
\text { A61B 3/113 } \\
\text { G06F 3/048 }\end{array}$ \\
\hline PI1001664-3 & (em sigilo) & IF Santa Catarina & (em sigilo) & $10 / 06 / 2010$ & (em sigilo) & (em sigilo) \\
\hline MU9002136-3 & (em sigilo) & IF Farroupilha & (em sigilo) & $16 / 07 / 2010$ & (em sigilo) & (em sigilo) \\
\hline PI1005213-5 & (em sigilo) & IF Ceará & (em sigilo) & $22 / 12 / 2010$ & (em sigilo) & (em sigilo) \\
\hline PI1013438-7 & (em sigilo) & $\begin{array}{l}\text { IF Bahia } \\
\text { Univ. Fed. Bahia }\end{array}$ & (em sigilo) & $23 / 12 / 2010$ & (em sigilo) & (em sigilo) \\
\hline MU9002752-3 & (em sigilo) & $\begin{array}{l}\text { IF Bahia } \\
\text { Univ. Fed. Sergipe }\end{array}$ & (em sigilo) & $24 / 12 / 2010$ & (em sigilo) & (em sigilo) \\
\hline MU9100280-0 & (em sigilo) & IF Bahia & (em sigilo) & $03 / 02 / 2011$ & (em sigilo) & (em sigilo) \\
\hline MU9100640-6 & (em sigilo) & IF Bahia & (em sigilo) & $14 / 03 / 2011$ & (em sigilo) & (em sigilo) \\
\hline PI1101586-1 & (em sigilo) & $\begin{array}{l}\text { IF Bahia } \\
\text { Univ. Fed. Sergipe }\end{array}$ & (em sigilo) & 15/04/2011 & (em sigilo) & (em sigilo) \\
\hline PI1101585-3 & (em sigilo) & $\begin{array}{l}\text { IF Bahia } \\
\text { Univ. Fed. Sergipe }\end{array}$ & (em sigilo) & $15 / 04 / 2011$ & (em sigilo) & (em sigilo) \\
\hline PI1 106613-0 & (em sigilo) & IF Bahia & (em sigilo) & $14 / 07 / 2011$ & (em sigilo) & (em sigilo) \\
\hline PI1106612-1 & (em sigilo) & IF Bahia & $(\mathrm{em}$ sigilo $)$ & $14 / 07 / 2011$ & (em sigilo) & (em sigilo) \\
\hline PI1104175-7 & (em sigilo) & IF Bahia & (em sigilo) & $20 / 07 / 2011$ & (em sigilo) & (em sigilo) \\
\hline PI1104949-9 & (em sigilo) & IF Ceará & (em sigilo) & $29 / 07 / 2011$ & (em sigilo) & (em sigilo) \\
\hline PI1106878-7 & (em sigilo) & IF Sertão PE & (em sigilo) & $02 / 08 / 2011$ & (em sigilo) & (em sigilo) \\
\hline PI1 106617-2 & (em sigilo) & $\begin{array}{l}\text { IF Minas Gerais } \\
\text { FAPEMIG }\end{array}$ & (em sigilo) & $11 / 10 / 2011$ & (em sigilo) & (em sigilo) \\
\hline PI1106418-8 & (em sigilo) & IF Ceará & (em sigilo) & $14 / 10 / 2011$ & (em sigilo) & (em sigilo) \\
\hline BR 1020120002612 & (em sigilo) & IF Bahia & (em sigilo) & $05 / 01 / 2012$ & (em sigilo) & (em sigilo) \\
\hline BR 2020120009833 & (em sigilo) & IF Bahia & (em sigilo) & $16 / 01 / 2012$ & (em sigilo) & (em sigilo) \\
\hline BR 1020120014238 & (em sigilo) & IF Bahia & (em sigilo) & $20 / 01 / 2012$ & (em sigilo) & (em sigilo) \\
\hline BR 1020120034336 & (em sigilo) & IF Sergipe & (em sigilo) & $15 / 02 / 2012$ & (em sigilo) & (em sigilo) \\
\hline BR 1020120077639 & (em sigilo) & IF Bahia & (em sigilo) & $04 / 04 / 2012$ & (em sigilo) & (em sigilo) \\
\hline BR 1020120090805 & (em sigilo) & IF Ceará & (em sigilo) & $18 / 04 / 2012$ & (em sigilo) & (em sigilo) \\
\hline BR 1020120090813 & (em sigilo) & IF Ceará & (em sigilo) & $18 / 04 / 2012$ & (em sigilo) & (em sigilo) \\
\hline BR 1020120103150 & (em sigilo) & IF Ceará & (em sigilo) & $02 / 05 / 2012$ & (em sigilo) & (em sigilo) \\
\hline BR 1020120105675 & (em sigilo) & IF Espírito Santo & (em sigilo) & $04 / 05 / 2012$ & (em sigilo) & (em sigilo) \\
\hline BR 1020120105772 & (em sigilo) & IF Espírito Santo & (em sigilo) & $04 / 05 / 2012$ & (em sigilo) & (em sigilo) \\
\hline BR 3020120027373 & (em sigilo) & IF Sudoeste MG & (em sigilo) & $31 / 05 / 2012$ & (em sigilo) & (em sigilo) \\
\hline BR 1020120178893 & (em sigilo) & IF Ceará & (em sigilo) & $19 / 07 / 2012$ & (em sigilo) & (em sigilo) \\
\hline BR 1020120178907 & (em sigilo) & IF Ceará & (em sigilo) & $19 / 07 / 2012$ & (em sigilo) & (em sigilo) \\
\hline
\end{tabular}

*Consulta em 31 de dezembro de 2012. 
**Até o final de 2011, classificação alfanumérica: MU8903003-6, onde: MU = natureza da proteção (para modelo de utilidade (MU), patente de invenção (PI), desenho industrial (DI) e indicação geográfica (IG); 89 = década do ano de depósito; 03003 = série numérica crescente, anual, composta de cinco algarismos e -6 = código de status da patente (BRANCO et al., 2011). A partir de 2012 novo formato: BR ZZ XXXX YYYYYY K, onde: BR = Código do país (Brasil); ZZ = Natureza da proteção (10 para patente de invenção, 20 para modelo de ultilidade, 30 para desenho industrial e 40 para indicação geográfica); XXXX = Ano de depósito no INPI; YYYYYY = Numeração que corresponde à ordem de depósito dos pedidos e K = Dígito verificador da numeração do pedido (INPI, 2013).

Fonte: Elaborado com as informações que constam nas patentes disponíveis no Banco de Dados do INPI.

A análise dos tipos de patentes depositadas pelos IFs foi realizada a partir dos códigos de identificação apresentados no Quadro 1 e conforme nota explicativa anexa ao referido Quadro. A Figura 2 mostra a distribuição das patentes por tipo.

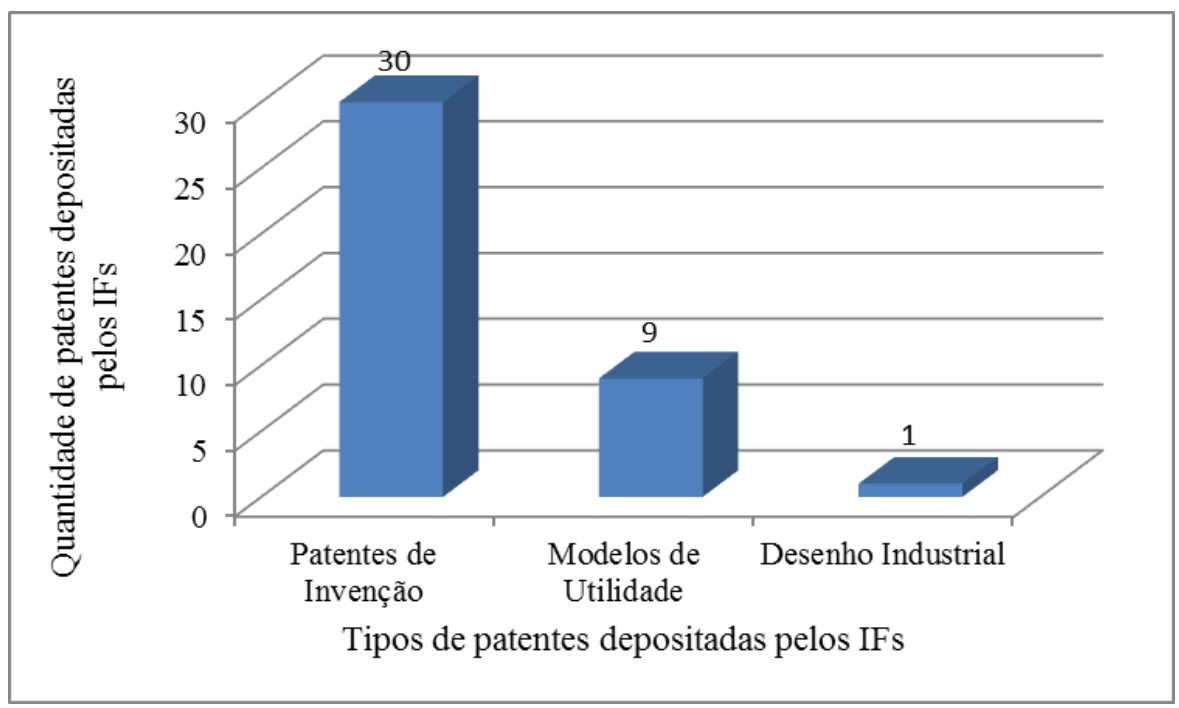

FIGURA 2 - Tipos de patentes depositadas pelos Institutos Federais de Educação, Ciência e Tecnologia. $(n=40)$

Fonte: Elaboração das autoras.

A prevalência das patentes de invenção está de acordo com Branco et al. (2011, p. 25), que afirma que "a patente de invenção é o instrumento mais utilizado na inovação tecnológica, pois cede a uma pessoa física ou jurídica o direito (temporário) de exclusividade comercial de uma invenção."

A origem das patentes foi inferida das instituições titulares, conforme a Figura 3. A distribuição das patentes por região geográfica mostrou maior produção na Região Nordeste. A Região Sudeste e a Região Sul aparecem com poucos depósitos de patentes. As instituições situadas nas regiões Centro-Oeste e Norte não depositaram patentes no período estudado. 


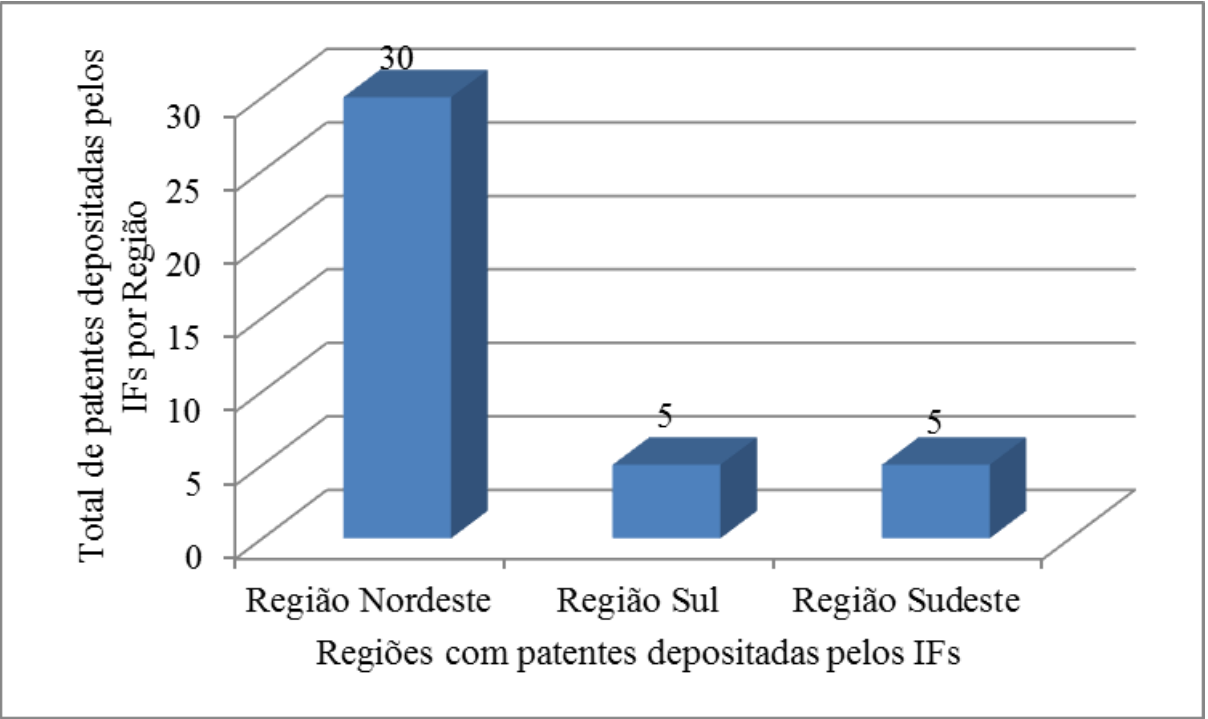

FIGURA 3 - Distribuição geográfica das patentes depositadas pelos Institutos Federais de Educação, Ciência e Tecnologia. $(n=40)$

Fonte: Elaboração das autoras.

Na Região Sudeste, até a data de corte deste levantamento, foram identificadas três patentes oriundas do IF do Espírito Santo, uma do IF do Sudoeste de Minas Gerais e uma do IF de Minas Gerais. Os IFs dos Estados do Rio de Janeiro e São Paulo não depositaram nenhuma patente, embora sejam estados economicamente mais desenvolvidos e concentrem mais recursos financeiros e agências de fomentos (GARCIA, 2006; OLIVEIRA; VELHO, 2009), sem contar as grandes indústrias e a Fundação de Amparo à Pesquisa do Estado de São Paulo (FAPESP) com quem os IFs poderiam formar parcerias. Por outro lado, existe produção significativa de patentes depositadas por universidades situadas nesses dois estados, inclusive em cotitularidade com a FAPESP. A razão da ausência de depósitos de patentes pelos IFs do Rio de Janeiro e de São Paulo e a concentração de depósitos feitos pelas universidades desses estados levantam questões que não serão respondidas neste trabalho, mas que apontam para possíveis dificuldades dos IFs no cumprimento de sua missão como estabelecida pela Lei que os criou, pelo menos nessa Região. Outro resultado que chama a atenção diz respeito às regiões Centro-Oeste e Norte, essas regiões não têm patente depositada. Da mesma forma, não existem estudos com produção de patentes pelas universidades dessas regiões. O motivo talvez se deva ao fato de serem regiões cujo desenvolvimento econômico é mais recente, mas é de conhecimento geral que existem indústrias instaladas nessas regiões. 
A Figura 4 mostra que o IF da Bahia é o que mais depositou de patentes no período estudado. Esse resultado aponta para um fato que distingue IFs de universidades, quando se considera quantidade de depósitos por regiões geográficas, pois, segundo Oliveira e Velho (2009) entre as universidades, a liderança dos depósitos de patentes ocorre no Estado de São Paulo (Região Sudeste).

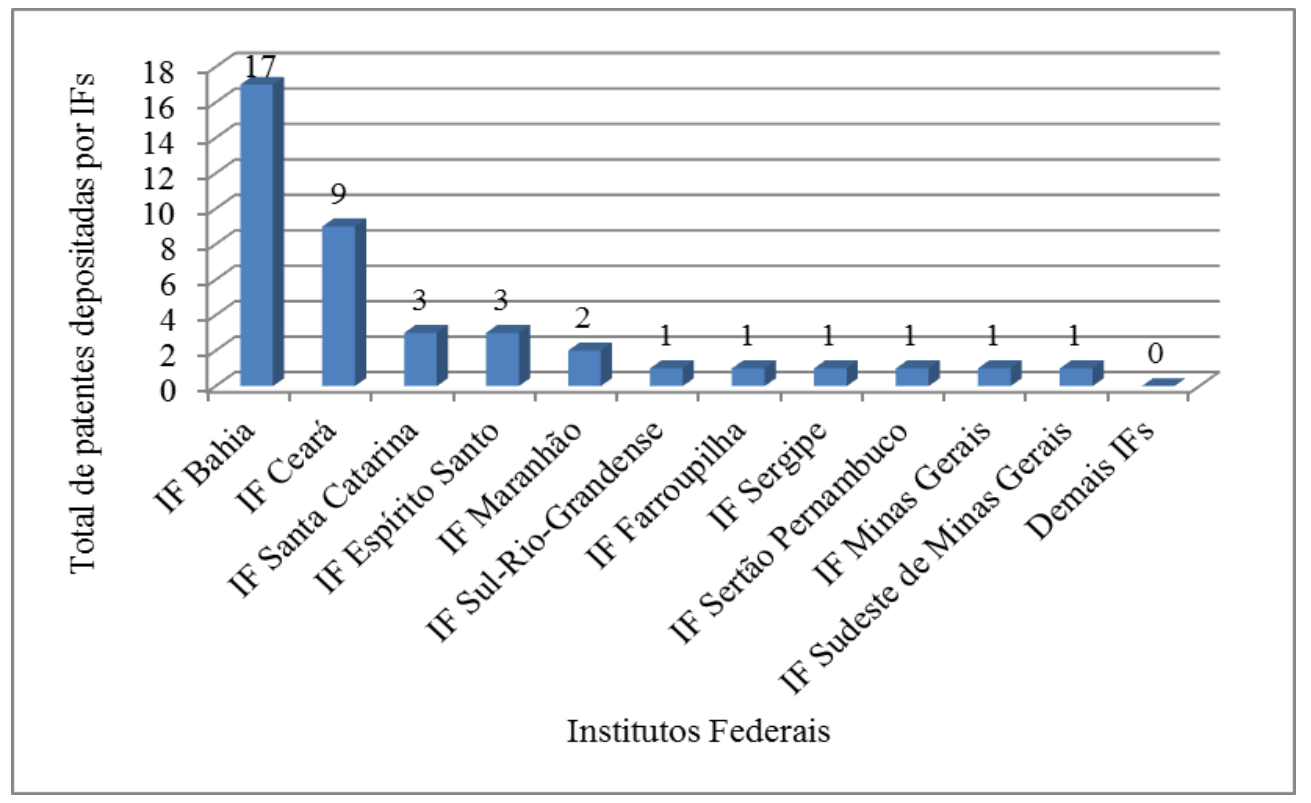

FIGURA 4 - Institutos Federais de Educação, Ciência e Tecnologia titulares das patentes depositadas. $(n=40)$.

Fonte: Elaboração das autoras.

Dos 38 IFs criados em 2008, apenas 11 depositaram patentes no período estudado. Os demais 27 IFs, até a data em que foi realizada a busca na Base de Dados do INPI, não tinham patentes depositadas. Esses 27 IFs são: IF Goiás; IF Goiano; IF Brasília; IF Mato Grosso; IF Mato Grosso do Sul; IF Baiano; IF Alagoas; IF Pernambuco; IF Paraíba; IF Rio Grande do Norte; IF Piauí; IF Amazonas; IF Amapá; IF Acre; IF Pará; IF Rondônia; IF Roraima; IF Tocantins; IF São Paulo; IF Norte de MG; IF Triângulo Mineiro; IF Sul de MG; IF Rio de Janeiro; IF Fluminense; IF Paraná; IF Catarinense e IF Rio Grande do Sul.

Foram identificadas, apenas nove patentes em parceria, predominando o titular individual (Quadro 1). O IF da Bahia figura como titular em sete parcerias, ás vezes com uma, duas ou três instituições: Serviço Nacional de Aprendizagem Industrial (SENAI); Universidade Federal da Bahia; Universidade Federal do Rio Grande do Norte e Universidade Federal de Sergipe. As outras duas patentes em parceria são: o 
IF do Espírito Santo com duas instituições, a Servigran Indústria e Comércio Ltda. e a Fundação de Amparo a Pesquisa do Espírito Santo (FAPES); e o IF de Minas Gerais que depositou patente junto com a Fundação de Amparo à Pesquisa do Estado de Minas Gerais (FAPEMIG). Examinando as patentes em parceiras, nota-se que sete entre as nove parcerias ocorreram com universidades federais, portanto mantendo a origem acadêmica da patente. Duas envolvem Fundações de Amparo à Pesquisa, também órgãos ligados ao governo, nesse caso, estadual. Apenas uma patente resultou de parceria com indústria privada, refletindo pouca interação entre instituições de ensino e indústria. A patente em parceira do IF da Bahia com o SENAI, órgão responsável pela formação de mão de obra qualificada para a indústria, poderia também ser considerada como envolvendo a indústria.

A quase total ausência de parcerias com indústrias aponta para uma situação característica do país, que mereceria um esforço específico dos IFs, tirando proveito do que está previsto na Lei de Inovação no 10.973 no Art. $3^{\circ}$ “A União, os Estados, o Distrito Federal, os Municípios e as respectivas agências de fomento poderão estimular e apoiar a constituição de alianças estratégicas e o desenvolvimento de projetos de cooperação envolvendo empresas nacionais, Instituição Científica e Tecnológica e organizações de direito privado sem fins lucrativos voltadas para atividades de pesquisa e desenvolvimento, que objetivem a geração de produtos e processos inovadores." (BRASIL, 2004).

A Figura 5 mostra a distribuição dos depósitos de patentes realizados pelos IFs no INPI, por ano. Note-se que em 2008 houve apenas dois depósitos, mas a partir de 2009 até 2012, data de corte da coleta dos dados, há aumento significativo. 


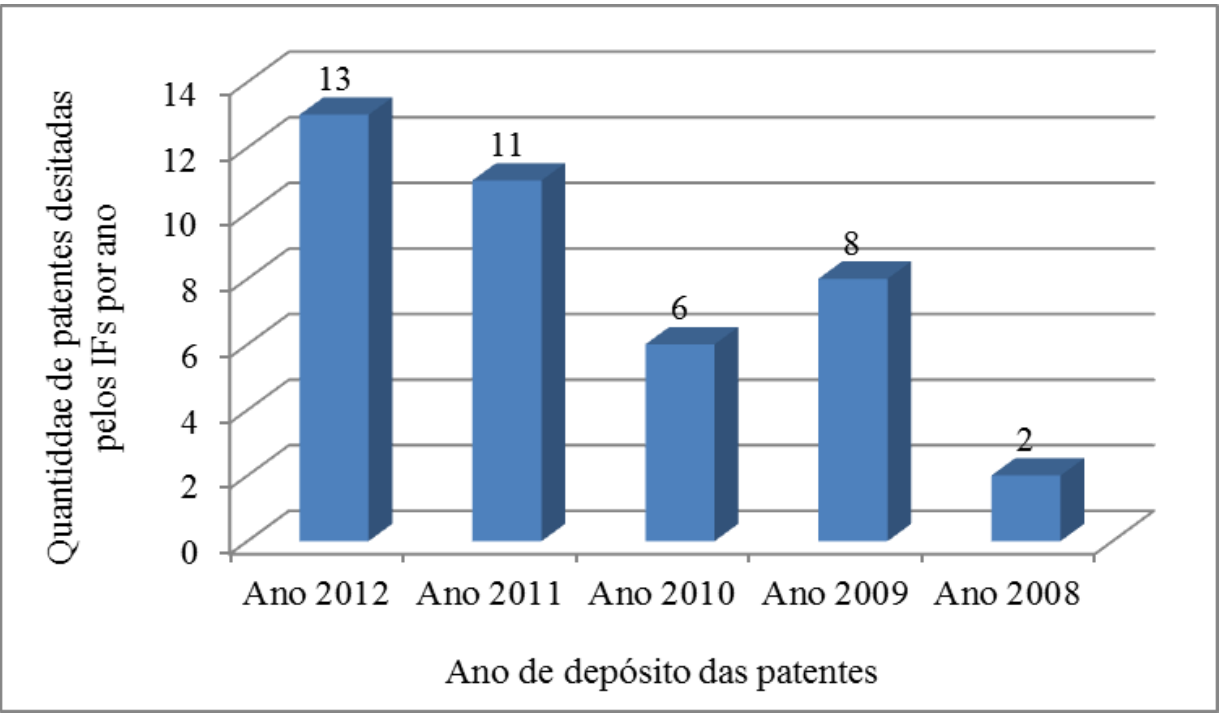

FIGURA 5 - Quantidade de patentes depositadas por ano pelos Institutos Federais de Educação, Ciência e Tecnologia. $(n=40)$

Fonte: Elaboração das autoras.

O aumento no número dos depósitos a partir do ano seguinte à promulgação da Lei 11.892, de 29/12/2008 que cria os IFs sugere relação entre os dois fatos, mas ainda é cedo para afirmar que esse seja o caso. Estudos futuros poderão confirmar ou não essa suposição.

A Figura 6 apresenta a distribuição das patentes por ano de publicação.

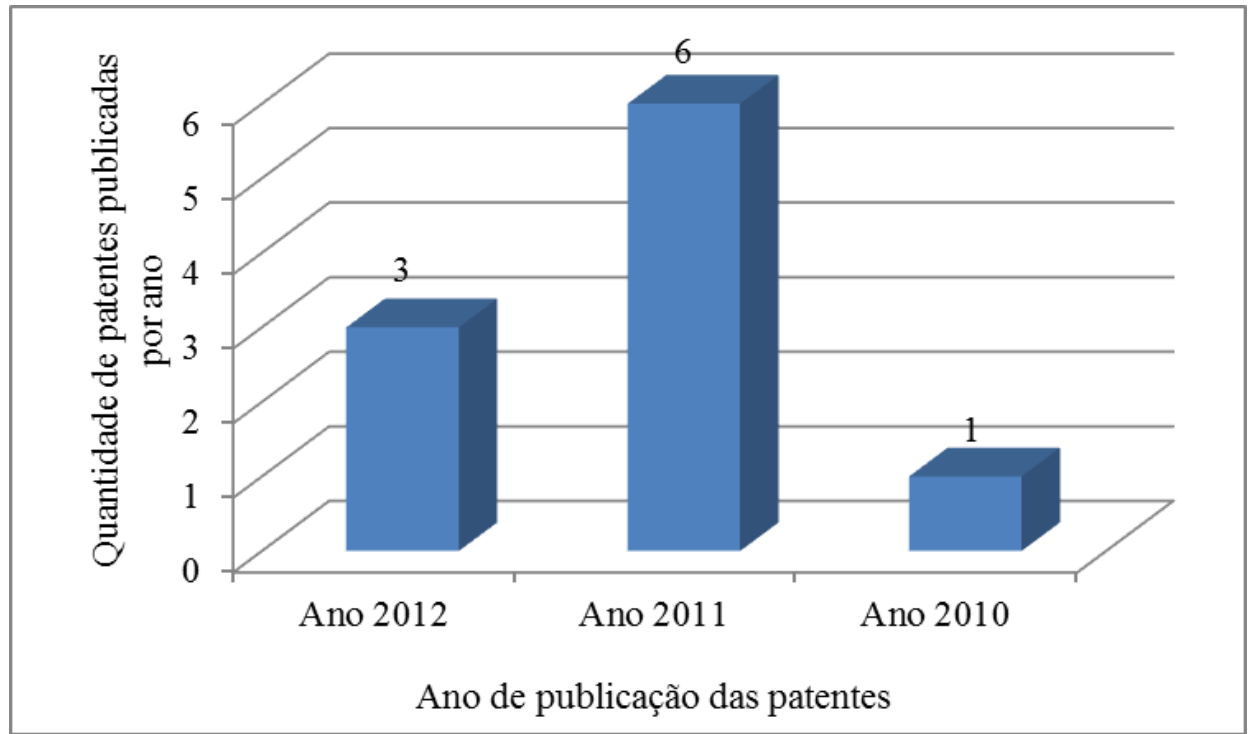

FIGURA 6 - Quantidade de patentes publicadas por ano pelos Institutos Federais de Educação, Ciência e Tecnologia. $(n=10)$

Fonte: Elaboração das autoras. 
Considerando-se os depósitos ocorridos em 2011 e 2012, e estendendo-se a tendência para 2013, o que é provável devido ao cumprimento do prazo estabelecido para validação de patentes em sigilo, pelo INPI, pode-se esperar um aumento considerável de patentes publicadas.

A patente, de acordo com Garcia (2006), é um documento formalizado por meio de um sistema que a registra, trata e dissemina, protegendo e garantindo o privilégio dos seus inventores. A indexação, etapa para posterior recuperação pelos usuários, é realizada por meio de uma classificação especialmente a ela destinada, a CIP, conhecida como International Patent Classification (IPC), foi estabelecida pelo Acordo de Estrasburgo em 1971 e prevê um sistema hierárquico de símbolos para a classificação de patente de invenção e de modelo de utilidade de acordo com as diferentes áreas tecnológicas a que pertencem. Note-se que uma mesma patente pode ser classificada em mais de uma seção e em várias classes, subclasses e grupos. Por isso, no Quadro 1, última coluna, para algumas patentes há várias classificações, às vezes na mesma seção mas em diferentes classes, subclasses ou grupos, às vezes em mais de uma seção e também em diferentes classes, subclasses ou grupos. Esta pesquisa focalizou apenas as seções, mas a soma das ocorrências, comentadas a seguir, extrapola o número de patentes publicadas por causa da classificação de algumas delas em mais de uma seção. As 10 patentes publicadas foram classificadas pelo INPI em cinco seções da CIP, especificamente: seção A (necessidade humana, sete patentes), C (química e metalurgia, quatro patentes) e $\mathrm{G}$ (física, quatro patentes), B (operações de processamento e transporte, uma patente) e F (engenharia mecânica, iluminação, aquecimento, armas e explosão, uma patente). Nenhuma patente foi registrada nas seções D (têxteis e papel), E (construções fixas) e H (eletricidade). Alguns títulos de seção são vagos e amplos demais, como a seção A - necessidades humanas, enquanto outros são bem específicos, como a seção C - química e metalurgia. Embora a abrangência da seção A possa sugerir uma explicação para a ocorrência maior de patentes nessa seção, a especificidade de outras não explica a ausência de patentes nessas classes. A razão da ocorrência ou ausência de depósitos nas diversas seções só poderá ser buscada com um estudo mais aprofundado, no qual, entre outros pontos, a vocação dominante de cada IF poderia ser identificada e relacionada à sua produção. 


\subsection{Resultados relacionados às variáveis inventores (patentes publicadas)}

Dado disponível apenas para as 10 patentes publicadas. No total, foram identificados 23 inventores de patentes, ás vezes assinando em parcerias. A Plataforma Lattes foi consultada para completar dados sobre esses inventores, revelando que 11 deles têm vínculo com um IF e outros seis inventores são de outras instituições e um é ex-aluno de um IF. Não foram encontrados dados de cinco inventores. De acordo com o objetivo proposto para este estudo apenas os 11 inventores que têm vínculo com IFs terão seu perfil delineado, construído a partir das variáveis de inventor, com dados obtidos na Plataforma Lattes.

Os dados relacionados às variáveis dos inventores - titulação, enquadramento funcional, existência de bolsa de produtividade, e a produção de outras patentes foram extraídos dos curricula vitae constantes da Plataforma Lattes. O exame dessas variáveis permitiu construir o perfil dos inventores, resumido no Quadro 2.

QUADRO 2 - Perfil dos inventores das patentes dos IFs. (n=11 inventores)

\begin{tabular}{|c|c|c|c|c|c|c|c|c|c|c|c|c|}
\hline \multicolumn{2}{|c|}{ SEXO } & \multicolumn{2}{|c|}{$\begin{array}{c}\text { BOLSA } \\
\text { PRODUTIVI } \\
\text { DADE } \\
\end{array}$} & \multicolumn{2}{|c|}{$\begin{array}{l}\text { GRUPOS } \\
\text { PESQUISA }\end{array}$} & \multicolumn{3}{|c|}{ TITULAÇÃO } & \multicolumn{2}{|c|}{$\begin{array}{l}\text { ENQUADRAMENTO } \\
\text { FUNCIONAL }\end{array}$} & \multicolumn{2}{|c|}{$\begin{array}{l}\text { OUTRAS } \\
\text { PATENTES }\end{array}$} \\
\hline M & $\mathrm{F}$ & Sim & Não & Sim & Não & Mestre & Doutor & $\begin{array}{c}\text { Pós } \\
\text { Doutorado } \\
\end{array}$ & Professor & $\begin{array}{c}\text { Técnico } \\
\text { Administrativo }\end{array}$ & Sim & Não \\
\hline 08 & 03 & 01 & 10 & 09 & 02 & 05 & 05 & 01 & 10 & 01 & 04 & 07 \\
\hline
\end{tabular}

Fonte: Elaborado a partir das informações do currículo na Plataforma Lattes

Os dados que constam no Quadro 2 são complementados com as seguintes informações:

1. Bolsas produtividade: o inventor que recebe bolsa tem pós-doutorado. Tipo de bolsa: Desenvolvimento Tecnológico e Extensão Inovadora do Conselho Nacional de Desenvolvimento Científico e Tecnológico (CNPq) nível 2.

2. Grupos de pesquisa: dos nove inventores que indicaram participar de grupos de pesquisa, quatro participam em mais de um.

3. O tempo de titulação ou formação acadêmica varia de três anos a vinte anos.

4. O tempo do enquadramento funcional no IF varia de 3 anos a18 anos .

A análise dos curricula vitae será comentada abaixo, conforme Quadro 2: o sexo masculino predomina entre os inventores, evidenciando a pouca representatividade feminina, apenas três pesquisadoras. A ausência de incentivos 
externos para 10 dos 11 inventores sugere que as patentes desenvolvidas por eles tenham sido motivadas por seu próprio interesse ou do IF ao qual pertencem. Nove inventores (inclusive o bolsista) fazem parte de grupos de pesquisa, o que sugere a importância dos grupos no estímulo ao desenvolvimento de pesquisas. Dez inventores com vínculo com IFs estão classificados como professores de ensino básico, técnico e tecnológico (de acordo com a Lei 11.784 de 22 de setembro de 2008); desses, quatro têm título de mestre, cinco têm título de doutor e um cumpriu estágio de pósdoutorado. O outro inventor é técnico administrativo e tem título de mestre.. Os IFs incentivam a atuação dos técnicos no desenvolvimento de pesquisa e depósitos de patentes, mas, apesar disso, este resultado chama a atenção pela baixa participação de técnicos. O exame dos curricula mostrou que quatro dentre os 11 inventores desenvolveram outras patentes além daquelas que constam no Quadro 1, mas que não foram incluídas neste estudo por terem sido depositadas em datas anteriores ou posteriores ao seu vinculo com IFs.

O perfil dos inventores relacionados aos IFs, apresentado acima, difere do perfil dos inventores com vínculo com universidades descrito por Oliveira e Velho (2009). De acordo com esses autores, os inventores ligados às universidades possuem pós-doutorado e livre docência, são bolsistas de Produtividade em Pesquisa do CNPq e lideram pelo menos um grupo de pesquisa. Oliveira e Velho (2009) associam o acúmulo de títulos e o desempenho acadêmico traduzido em bolsas de produtividade diretamente aos resultados alcançados pelos pesquisadores das universidades ao longo do tempo. Talvez essa informação justifique a diferença dos depósitos de patentes entre as universidades e os IFs.

\section{CONSIDERAÇÕES FINAIS}

Verificou-se, em resposta ao questionamento inicial, que houve um aumento na produção de patentes e nas solicitações de patentes pelos IFs, registradas no INPI entre 2011 e 2012. Apesar de o aumento ter ocorrido após a implementação da Lei 11.892 em 2008 que criou os IFs, não se pode afirmar que esse salto no número de registros se deva exclusivamente a esse fato, pois estudos sobre patentes universitárias (não apenas IFs) apontam crescimento significativo desde o início deste século 21 , entre eles Oliveira e Velho, (2009), Póvoa (2008 e 2010). Mais provavelmente a 
explicação se deva a um conjunto de fatores políticos e econômicos, entre os quais a promulgação da Lei da Inovação, ela própria, assim como os IFs, produto de um esforço mais amplo do País rumo ao desenvolvimento tecnológico.

Embora a produção de 40 patentes pelos IFs pareça pouco quando comparada à produção de patentes pelas universidades públicas, deve-se considerar que o objetivo principal das instituições que precederam os IFs era a educação em nível médio de técnicos aptos para o trabalho na sociedade. Em certa medida, esse também é hoje um dos principais objetivos dos IFs. A produção de 40 patentes depositadas a partir de 2008 poderia, ao contrário, ser interpretada como um indício de que os IFs estão evoluindo para o cumprimento de sua função como descrita na lei e estão produzindo tecnologia.

O destaque da Região Nordeste como maior produtor de patentes depositadas e publicadas, especialmente o IF da Bahia, o maior depositante, deixa em aberto uma questão para futuros estudos, em busca de uma explicação. O sucesso do IF da Bahia e o fato de ter sido a instituição que mais produziu em parcerias aumenta o interesse por um futuro estudo. Por outro lado, a baixa ocorrência de parcerias no conjunto estudado, apenas nove patentes em 40, parece apontar para o desinteresse da indústria nacional em relação às pesquisas acadêmicas.

Dois últimos pontos poderiam ser comentados, a questão da natureza das patentes e a participação feminina. Quanto ao primeiro, o maior número de ocorrências se deu na seção A (necessidades humanas). Neste estudo considerou-se apenas o nível das seções, no qual consta essa expressão, muito ampla, dificultando visão clara do que seria classificado aí e não em outras seções. Talvez a pergunta a ser feita seja o porquê do menor número e em vários casos, ausência, de patentes nas outras seções. A baixa participação feminina, pouco mais que um terço dos inventores, talvez decorra de uma limitação histórica da presença da mulher em áreas tecnológicas. Por outro lado, essa situação está mudando rapidamente em muitas sociedades, também no Brasil.

O fato que existe e que está aumentado significativamente atividade de pesquisa que resulta em patentes depositadas e publicadas sugere não apenas que é possível conciliar pesquisa visando ao entendimento com pesquisa visando à 
utilização, como defende Stokes, mas também sugere estar havendo mudança na mentalidade das comunidades acadêmicas sobre essa questão. Pode-se incluir aí os estudiosos da área de Ciência da Informação, que começam a prestar mais atenção às patentes como tema de estudo.

Há vários aspectos que poderiam ser estudados com as patentes dos IFs, como por exemplo, uma análise da descrição do estado da arte e desenvolvimento técnico das patentes; reivindicações das patentes; estudo das patentes como fonte de informação; o comportamento do inventor envolvido no processo de proteção, um estudo das citações de patentes produzidas e a existência de Núcleos de Inovação Tecnológica nos IFs. Se a produção de patentes no país continuar crescendo na proporção verificada neste levantamento, não faltará material a ser estudado. 


\section{REFERÊNCIAS}

AMADEI, José Roberto P.; TORKOMIAN, Ana Lúcia V. As patentes nas universidades: análise dos depósitos das universidades públicas paulistas. Ciência da Informação, Brasília, v. 38, n. 2, p. 9-18, maio/ago., 2009. Disponível em: $<$ http://revista.ibict.br/ciinf/index.php/ciinf/article/view/1054/>. Acesso em: 14 jun. 2012.

ASSUMPÇÃO, Eduardo. A utilização do sistema de patentes pelas universidades brasileiras nos anos 90. Rio de janeiro: INPI, 2000.

BRANCO, Gilberto et al. Propriedade intelectual. Curitiba: Aymará, 2011.

BRASIL. Lei no 9.279, de 14 de maio de 1996. Regula direitos e obrigações relativos à propriedade industrial. Disponível em: <http://www.planalto.gov.br/ccivil 03/leis/L9279.htm>. Acesso em: 16 jul. 2012.

BRASIL. Lei $\mathbf{n}^{\mathbf{0}} \mathbf{1 0 . 9 7 3}$, de 2 de Dezembro de 2004. Dispõe sobre incentivos à inovação e à pesquisa científica e tecnológica no ambiente produtivo e dá outras providências. Disponível em: <http://www2.camara.gov.br/legin/fed/lei/2004/lei10973-2-dezembro-2004-534975-publicacaooriginal-21531-pl.html>. Acesso em: 16 jul. 2012.

BRASIL. Lei $\mathbf{n}^{\mathbf{0}} \mathbf{. 1 1 . 8 9 2}$, de 29 de dezembro de 2008. Institui a Rede Federal de Educação Profissional, Científica e Tecnológica. Cria os Institutos Federais de Educação, Ciência e Tecnologia, e dá outras providências. Disponível em: <http://www.planalto.ov.br/ccivil/Ato2007_2010/2008/L11892 >. Acesso em: 23 jan. 2009.

BUSH, Vannevar. Science the endless frontier: a report to the President on a Program for Postwar Scientific Research. Washington: National Science Foundation, 1945.

CASTRO, Alexandre Camargo; JANNUZZI, Celeste Aída Sirotheau Corrêa; MATTOS, Fernando Augusto Mansor de. Produção e disseminação de informação tecnológica: a atuação da Inova - Agência de Inovação da UNICAMP.

Transinformação, Campinas, v. 19, n. 3, p. 265-277, set./dez. 2007. Disponível em: <http://revistas.puc-campinas.edu.br/transinfo/viewissue.php>. Acesso em: 28 set. 2012.

FRANÇA, Ricardo Orlandi. A patente. In: CAMPELLO, Bernadette Santos; CENDÒN, Beatriz Valadares; KREMER, Jeanette Marguerite (Orgs.). Fontes de informação para pesquisadores e profissionais. Belo Horizonte: Editora UFMG, 2000. Cap.12, p.: 152-182.

GARCIA, Joana Coeli Ribeiro. Os paradoxos da patente. DataGramaZero - Revista de Ciência da Informação. v. 7, n. 5, out. 2006. Disponível em:

< http://www.dgz.org.br/out06/Art 04.htm>. Acesso em: 13 maio 2012. 
INPI. Instituto Nacional da Propriedade Industrial. Guia básico: patentes. 2013. Disponível em: <http://www.inpi.gov.br/portal/artigo/guia_basico_patentes $>$. Acesso em 02 maio 2013.

INPI. Classificação - Patentes. 2011. Disponível em:

<http://pesquisa.inpi.gov.br/patentes/classificacao.htm>. Acesso em: 11 maio 2012.

JANNUZZI, Anna H. L.; SOUZA, Cristina G. de. Patentes de invenção e artigos científicos: especificidades e similitudes. RBPG - Revista Brasileira de PósGraduação, Brasília, v. 5, n. 9, p. 03-125, dez. 2008.

MACEDO, Maria Fernanda G.; BARBOSA, A. L. Patentes, pesquisa e desenvolvimento: um manual de propriedade intelectual. Rio de Janeiro: Fiocruz, 2000 .

OCDE. Organización para la Cooperación y el Desarrollo Económicos. Manual de estadísticas de patentes de la OCDE. [Espanha; Madri]: OCDE, 2009.

OLIVEIRA, Rodrigo Maia de; VELHO, Léa Maria L. S. Patentes acadêmicas no Brasil: uma análise sobre as universidades públicas paulistas e seus inventores. Parcerias Estratégicas, Brasília, v. 14, n. 29, p. 173-200, jul./dez, 2009. Disponível em: 〈http://www.cgee.org.br/atividades/redirKori/6007>. Acesso em: 14 jun. 2012.

PÓVOA, Luciano Martins Costa. Patentes de universidades e institutos públicos de pesquisa e a transferência de tecnologia para empresas no Brasil. 2008. 153 f. Tese (Doutorado em Economia) - Centro de Desenvolvimento e Planejamento Regional, Faculdade de Ciências Econômicas, Universidade Federal de Minas Gerais, Belo Horizonte, 2008. Disponível em:

<http://www.bibliotecadigital.ufmg.br/dspace/handle/1843 >. Acesso em: 22 jun. 2012.

PÓVOA, Luciano Martins Costa. A universidade deve patentear suas invenções?

Revista Brasileira de Inovação, Rio de Janeiro, v. 9, n. 2, p. 231-256, jul./dez. 2010. Disponível em: 〈http://www.ige.unicamp.br/ojs/index.php/rbi/article/view/474>. Acesso em: 28 set. 2012.

SPINAK, Ernesto. Indicadores cienciométricos de patentes: aplicaciones y limitaciones. 2003. Disponível em:

< http://cmapspublic.ihmc.us/rid=1206948788468_1666271724_19616/Spinak.pdf> . Acesso em: 02 maio 2013.

SERAFINI, Mairim Russo et al. Características da propriedade intelectual no nordeste através de sites de buscas tecnológicas. Revista GEINTEC: gestão, inovação e tecnologias, São Cristóvão/SE, v. 1, n. 1, p. 01-11, 2011. Disponível em: <http://www.revistageintec.net/portal/index.php/revista/article $>$. Acesso em: 15 jun. 2012. 
SOUZA, Cristina Gomes de; BARBASTEFANO, Rafael Garcia; PEREIRA, Fernanda de Carvalho. Estudo sobre o perfil dos inventores das patentes de universidades brasileiras. In: ENCONTRO NACIONAL DE ENGENHARIA DE PRODUCAO, 31, 2011, Belo Horizonte. Anais... Belo Horizonte: ABREPO, 2011. Disponível em: 〈http://www.abepro.org.br/.../enegep2011_TN_STO_142.pdf >. Acesso em: 02 jun. 2012.

STOKES, Donald E. O quadrante de Pasteur: a ciência básica e a inovação tecnológica. Campinas: UNICAMP, 2005.

UM SÉCULO de constante evolução. 2009? Disponível em: <http://portal.mec.gov.br/setec/arquivos/centenario/mapa.pdf $>$. Acesso em: $20 \mathrm{de}$ dezembro de 2012.

\section{Como citar este artigo:}

PERUCCHI, Valmira; MUELLER, Suzana Pinheiro Machado.Estudo com as patentes produzidas e o perfil dos inventores dos Institutos Federais de Educação, Ciência e Tecnologia. Rev. digit. bibliotecon. cienc. inf., Campinas, SP, v.12, n.1, p.191-213, jan/abr. 2014. ISSN 1678-765X. Disponível em: <http://www.sbu.unicamp.br/seer/ojs/index.php/rbci> 